\title{
Immunoexpression of c-erbB-2 and p53 in benign and malignant salivary neoplasms with myoepithelial differentiation
}

\author{
Joaninha Costa Rosa, Ana Félix, Isabel Fonseca, Jorge Soares
}

\begin{abstract}
Aim-To evaluate whether the immunoexpression of c-erbB-2 and p53 is involved in the pathogenesis and progression of salivary tumours with myoepithelial differentiation.

Methods-233 tumours from 211 patients were studied. These included 76 primary and 24 recurrent adenocarcinomas (polymorphous low grade adenocarcinoma, 13; epithelial-myoepithelial carcinoma, 19; adenoid cystic carcinoma, 56; and basal cell adenocarcinoma, 12) and 133 pleomorphic adenomas and myoepitheliomas, 96 being primary and the remaining recurrent tumours. All cases were formalin fixed and paraffin wax embedded. A StrepABC peroxidase method and polyclonal c-erbB-2 and p53 specific antisera were used.
\end{abstract}

Results-Cell membrane staining of c-erbB-2 was not found in any benign or malignant tumour. There was p53 protein accumulation in one primary and one recurrent pleomorphic adenoma and in $\mathbf{1 0}$ adenocarcinomas (polymorphous low grade adenocarcinoma, one; epithelialmyoepithelial carcinoma, one; adenoid cystic carcinoma, five; and basal cell adenocarcinoma, three), three of them being recurrences.

Conclusions-The c-erbB-2 and p53 proteins are not involved in the pathogenesis of pleomorphic adenoma and myoepithelioma and do not constitute biomarkers in assessing the risk of recurrence. c-erbB-2 is not involved in the genesis of low grade salivary neoplasia with myoepithelial differentiation. The percentage of this type of neoplasia with p53 accumulation is low (10\%) and does not appear to be related to tumour recurrence.

$(\Im$ Clin Pathol 1997;50:661-663)

Keywords: p53; c-erbB-2; salivary gland neoplasms

p53 is a nuclear phosphoprotein encoded by a gene located on the short arm of chromosome 17 (17p13.1) and the c-erbB-2 protein is a growth factor receptor encoded at a different region of the same chromosome (17q11.2-12). Both the overexpression of c-erbB- 2 and the accumulation of the p53 protein have been reported in a wide variety of human tumours, including those originating in salivary glands. ${ }^{1-9}$ However, there is some controversy about this issue, and the literature is occasionally conflicting, which justifies further investigations to clarify the involvement of both genes and their products in the tumorigenesis of salivary glands.

It is well known that the majority of benign and malignant salivary gland neoplasms show dual differentiation, with a composite epithelial and myoepithelial phenotype. Our previous studies of malignant mixed tumours ${ }^{10}{ }^{11} \mathrm{dem}$ onstrated p53 and c-erbB-2 immunoexpression in high grade carcinomatous areas but not in the benign components, or in the low grade malignant areas, which usually exhibit a modified myoepithelial cell phenotype. These observations suggested that alterations of these protein products are associated with the acquisition of a certain malignant phenotype, supporting the view that low and high grade adenocarcinomatous components of carcinoma ex-pleomorphic adenomas (with and without myoepithelial differentiation, respectively) are related to distinct histogenetic pathways. $^{1011}$

The aim of this study was to confirm these conclusions in salivary gland tumours with similar histology but outside the context of malignant transformation of pleomorphic adenoma. We evaluated p53 and c-erbB-2 immunoexpression in a large series of myoepithelial cell related salivary gland neoplasms, including pleomorphic adenomas, myoepitheliomas, and low grade adenocarcinomas, in an attempt to substantiate our previous results and to evaluate the potential role of the aforementioned proteins in tumour recurrence and progression.

\section{Materials and methods}

This study was performed on 233 salivary gland tumours: 133 pleomorphic adenomas and myoepitheliomas from 111 patients, and 100 low grade adenocarcinomas from an equal number of patients treated at the Instituto Português de Oncologia de Francisco Gentil, Lisboa, Portugal.

The age of the patients ranged between 10 and 92 years, 67 patients were male and 144 female. In one case the patient's age was not recorded.

In the group of patients with benign tumours, 29 had recurrent disease. From these, 14 primaries and 37 recurrent tumours (from 23 patients) were assessed for comparison. The remainder were not studied because the archival tissue was not available, or recurrence had 
Table 1 Results of p53 and c-erbB-2 immunostaining in benign neoplasms (pleomorphic adenoma and myoepithelioma)

\begin{tabular}{lccc}
\hline Tumour type & $n$ & $\begin{array}{l}\text { Number } \\
\text { examined }\end{array}$ & p53/c-erbB-2 \\
\hline Non-recurrent primary tumour & 82 & 82 & $1 / 0$ \\
Primary tumour with further recurrences & 29 & 14 & $0 / 0$ \\
First recurrence & 28 & 18 & $0 / 0$ \\
Second recurrence & 13 & 13 & $1 / 0$ \\
Third recurrence & 3 & 3 & $0 / 0$ \\
Fourth recurrence & 3 & 3 & $0 / 0$ \\
Total & 158 & 133 & $2 / 0$ \\
\hline
\end{tabular}

* The case that recurred as a malignant mixed tumour is not included. This was positive for $\mathrm{p} 53$ in the adenocarcinomatous component of the tumour.

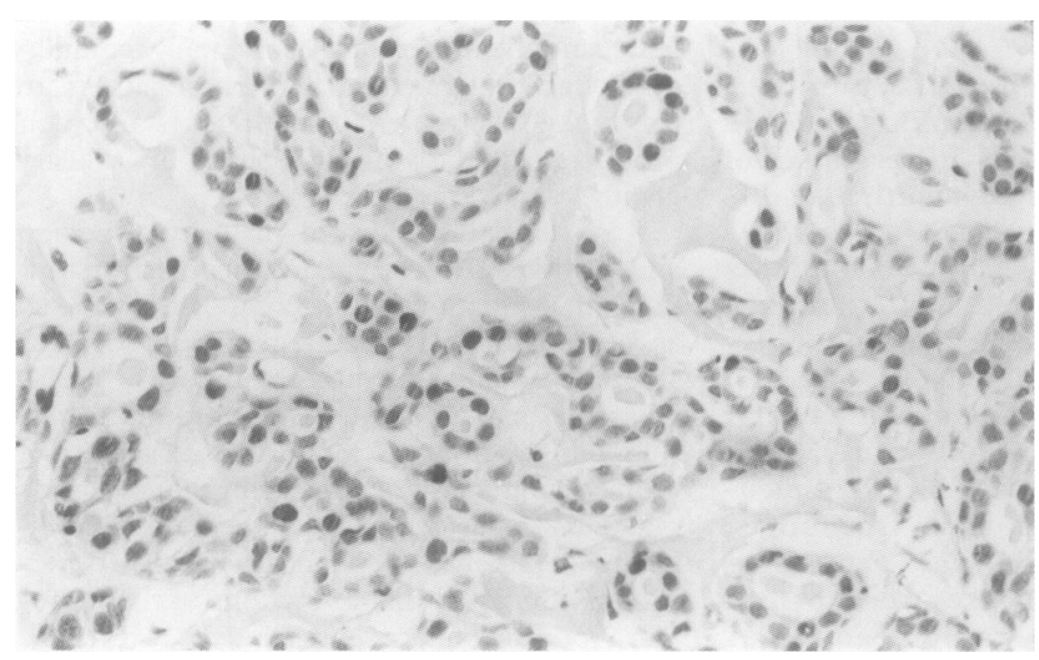

Figure 1 The nuclear staining of p53 in adenoid cystic carcinoma (original magnification, $\times 333$ ).

been diagnosed by fine needle aspiration cytology. One tumour recurred as a carcinoma ex-pleomorphic adenoma, and this recurrence was not included in the present study.

In the adenocarcinoma group we analysed 76 primary neoplasms and 24 recurrences. The adenocarcinomas were classified as: polymorphous low grade adenocarcinoma $(n=13)$, epithelial-myoepithelial carcinoma $(n=19)$, adenoid cystic carcinoma $(n=56)$, and basal cell adenocarcinoma $(n=12)$. Radiation therapy had been carried out in nine patients, eight with adenoid cystic carcinoma and one with epithelial-myoepithelial carcinoma.

Haematoxylin and eosin stained sections of each tumour were re-examined and one representative paraffin block was selected for the immunohistochemical study. Sections ( $4 \mu \mathrm{m}$ thick) were collected on to gelatine coated slides, dewaxed in xylene, and rehydrated through ethanol. Endogenous peroxidase was blocked with $0.3 \% \mathrm{H}_{2} \mathrm{O}_{2}$ in methanol, for 10 minutes, at room temperature.

For p53 staining, high temperature antigen unmasking and incubation with rabbit polyclo-

Table 2 Results of p53 and c-erbB-2 immunostaining in salivary adenocarcinomas with myoepithelial participation

\begin{tabular}{llll}
\hline Tumour type & $\begin{array}{l}\text { Number } \\
\text { examined }\end{array}$ & $p 53$ positive cases $(\%$ of $+v e$ cells $)$ & $c$-erbB-2 +ve cases \\
\hline PLGA & 13 & $1(>10 \%)$ & 0 \\
EMC & 19 & $1(>25 \%)$ & 0 \\
ACC & 56 & $5(>10 \%$ in $3 ;>25 \%$ in 2$)$ & 0 \\
BCA & 12 & $3(>10 \% ;>50 \%$ and $>75 \%)$ & 0 \\
Total & 100 & 10 & 0
\end{tabular}

PLGA, polymorphous low-grade adenocarcinoma; EMC, epithelial-myoepithelial carcinoma ACC, adenoid cystic carcinoma; BCC, basal cell adenocarcinoma. nal p53 specific antibody (CM1; Novocastra, Newcastle upon Tyne, UK) diluted $1 / 3000$, for 30 minutes, was carried out. For c-erbB-2 immunostaining, a polyclonal c-erbB-2 specific antibody (A485; Dako, Glostrup, Denmark) diluted $1 / 150$, for 30 minutes, at room temperature, was used. All slides were then incubated with a secondary biotinylated antirabbit antibody (Dako) diluted $1 / 250$, for 30 minutes, at room temperature and StrepABC conjugated with peroxidase $(1+1+100)$ for 30 minutes, at room temperature. Diaminobenzidine tetrahydrochloride solution was used as chromogen. Appropriate control procedures were used.

Tissues were considered to be $\mathrm{p} 53$ positive when brown stained nuclei were observed in more than $10 \%$ of tumour cells. The percentage of p53 positive nuclei was semiquantitatively assessed and scored as $>10 \%$ but $\leqslant 25 \%, \quad 25-50 \%, \quad 50-75 \%$, and $>75 \%$. c-erbB-2 immunostaining was considered positive when the neoplastic cells exhibited a distinct cell membrane decoration.

\section{Results}

PLEOMORPHIC ADENOMAS AND MYOEPITHELIOMAS

c-erbB-2 immunoexpression was consistently negative in all 133 cases. p53 positivity was obtained in more than $10 \%$ of the neoplastic cells in one primary neoplasm and in one recurrent tumour (second recurrence). In the latter case, both the primary tumour and the first recurrence were negative (table 1 ).

Normal salivary gland tissue adjacent to neoplasms was consistently negative for both antibodies.

\section{ADENOCARCINOMAS WITH MYOEPITHELIAL}

DIFFERENTIATION

Immunoexpression of c-erbB-2 was not found in any of the 100 cases. In situ ductal carcinoma of the breast, used as a c-erbB-2 positive control, displayed uniformly marked brown staining of the neoplastic cell membrane.

Accumulation of p53 was observed in 10 cases of adenocarcinoma (fig 1): one case of epithelial-myoepithelial; one polymorphous low grade adenocarcinoma; five adenoid cystic carcinoma; and three basal cell adenocarcinoma (table 2). Three of the positive cases were recurrent tumours. The percentages of positive cases among the groups of primary and recurrent neoplasms were $9.2 \%$ (7 of 76 ) and $12.5 \%$ (3 of 24), respectively.

Nuclear immunoexpression of p53 was distributed diffusely throughout the tumour section, without cell type preference, and irrespective of the histological type. Differences in staining intensity were not taken into account. p53 was found to be positive in two of nine cases previously submitted to local radiotherapy.

\section{Discussion}

Frequently, recurrence of pleomorphic adenoma is associated with either incomplete excision of the lesion or tumour capsule 
disruption during surgical removal. Malignant change occurs in $3-4 \%$ of all pleomorphic adenomas ${ }^{12}$ and is associated with longstanding and recurrent tumours. ${ }^{13}$

In this study, the immunoexpression of p53 was very low and c-erbB-2 was not immunoexpressed, either in primary or recurrent pleomorphic adenoma, suggesting that these genes are not involved in the pathogenesis of these neoplasms, or in their potential for recurrence. Likewise, they do not seem to constitute biomarkers for the assessment of the risk of their malignant transformation.

These findings support our previous results obtained in the study of a series of carcinoma ex-pleomorphic adenomas ${ }^{10}{ }^{11}$ in which p 53 and c-erbB-2 expression was found to be consistently negative in the benign areas of the tumours. In those studies, p53 and c-erbB-2 immunoexpression was found exclusively in the high grade malignant neoplastic components.

The present study also shows that malignant salivary gland neoplasms with evidence of myoepithelial lineage do not overexpress c-erbB-2 protein. In fact, none of the 100 adenocarcinomas showed cell membrane staining, which supports the view that this growth factor receptor is not involved in their pathogenesis. This conclusion is in accordance with previous studies ${ }^{2514}$ performed in cases of salivary gland carcinomas with myoepithelial differentiation but differs from the results obtained by Kärjä et al. ${ }^{3}$

In contrast to our observations in this series of low grade adenocarcinomas, the c-erbB-2 protein is expressed overtly by high grade salivary carcinomas, namely salivary duct carcinoma ${ }^{15}{ }^{16}$ and high grade mucoepidermoid carcinoma. ${ }^{17}$ This gives further support to the existence of distinct molecular mechanisms in salivary gland carcinogenesis.

The p53 protein was detected in a small number of low grade salivary adenocarcinomas, irrespective of their histological subtype. The percentage $(10 \%)$ of positive cases may be overestimated as, in two of the 10 positive tumours, the patients had received radiotherapy. It is known that cell irradiation can induce $\mathrm{p} 53$ wild-type protein accumulation ${ }^{18}$ and, therefore, may be responsible for false positive results that are not mutation associated.

There is some variation in the literature regarding the frequency of p53 alterations in myoepithelial lineage adenocarcinomas of the salivary glands. ${ }^{5-9}$ Distinct methodologies, criteria for positivity, sample types, and subjectivity of the histological classifications are some of the main factors that might explain the disparate results.

To evaluate whether recurrent malignant adenocarcinomas express p53 more frequently than primary neoplasms a large number of lesions was studied by immunohistochemistry. We verified that the percentage of positivity among primary $(9.2 \%)$ and recurrent $(12.5 \%)$ tumours did not differ significantly. In a previous study of a small number of cases, Papadaki et $a l^{19}$ suggested that p53 mutation was involved in tumour recurrence. However, the discrepancy of results could be explained by the sample sizes, distinct methodologies, and assessment criteria. In fact, we considered cases containing more than $10 \%$ of p53 stained nuclei as positive, assuming that it would be more likely that occasional positive cells $(\leqslant 10 \%)$ distributed throughout the histological section would be related to stabilisation/ accumulation of the protein, rather than to $\mathrm{p} 53$ mutation. Whatever the reasons for the existence of a certain number of $\mathrm{p} 53$ positive dispersed cells, in our study, they occurred in 11 primary lesions and only one recurrent lesion, reinforcing the assumption that tumour recurrence is not related to $\mathrm{p} 53$ gene alterations.

This work was supported by a grant from the Núcleo Regional do Sul da Liga Portuguesa Contra o Cancro. The authors thank Mrs Alexandra Teixeira for technical assistance.

1 Kernohan NM, Blessing K, King G, Corbett IP, Miller ID. Expression of c-erbB-2 oncoprotein in salivary gland tumours: an immunohistochemical study. $\mathcal{f}$ Pathol 1991;163:77-80.

2 Shrestha P, Huang JW, Tsuji T, Shinozaki F, Maeda K, Sasaki K, et al. Rare expression of the c-erbB-2 oncoprotein in salivary gland tumors: an immunohistochemical study. $\mathcal{F}$ Oral Pathol Med 1992;21:477-80.

3 Kärjä V, Syrjänen S, Kataja V, Syrjänen K. c-erbB-2 oncogene expression in salivary gland tumours. ORL 1994; 56:206-12.

4 Sugano S, Mukai K, Tsuda H, Hirohashi S, Furuya S, Shimosato $\mathrm{Y}$, et al. Immunohistochemical study of c-erbB-2 oncoprotein overexpression in human major salivary gland carcinoma: an indicator of aggressiveness. Laryngoscope 1992;102:923-7.

5 Kamio N. Coexpression of p53 and c-erbB-2 proteins is associated with histological type, tumour stage, and cell proliferation in malignant salivary gland tumours. Virchows Arch 1996;428:75-83.

6 Deguchi H, Hamano H, Hayashi Y. c-myc, ras p21 and p53 expression in pleomorphic adenoma and its malignan form of the human salivary glands. Acta Pathol fpn 1993;43:413-22.

7 Ishi K, Nakajima T. Evaluation of malignant grade of salivary gland tumours: studies by cytofluorometric nuclear DNA analysis, histochemistry for nucleolar organizer regions and immuno-histochemistry for p53. Pathol In 1994;44:287-96.

8 Soini Y, Kamel D, Nurova K, Lane DP, Vahakangas K, Paakko P. Low p53 protein expression in salivary gland tumors compared to lung carcinomas. Virchows Arch $A$ Pathol Anat Histopathol 1992;421:415-20.

9 Gallo O, Franchi A, Bianchi S, Boddi V, Gianelli E, Alajmo E. p53 oncoprotein expression in parotid gland carcinoma is associated with clinical outcome. Cancer 1995;75:203744.

10 Rosa JC, Fonseca I, Félix A, Soares J. Immunohistochemical study of c-erbB-2 expression in carcinoma ex-pleomorphic study of c-erbB-2 expression in carcinoma
adenoma. Histopathology 1996;28:247-52.

11 Rosa JC, Fonseca I, Félix A, Soares J. p53 immunoexpression in carcinomas arising in pleomorphic adenoma. Int $\mathcal{f}$ Surg Pathol 1996;3:257-62.

12 Seifert G. Histopathology of malignant salivary gland tumours. Oral Oncol Eur f Cancer 1992;28B:49-56.

13 Gnepp DR. Malignant mixed tumors of salivary glands: a review. Pathol Ann 1993;28:279-328.

14 Cho KJ, El-Naggar AK, Ordonez NG, Luna MA, Austin J, Batsakis JG. Epithelial-myoepithelial carcinoma of salivary glands. A clinicopathologic, DNA flow cytometric, and immunohistochemical study of $\mathrm{Ki} 67$ and HER-2/neu oncogene. Am f Clin Pathol 1995;103:432-7.

15 Hellquist HB, Karlson MG, Nilsson C. Salivary duct carcinoma - a highly aggressive salivary gland tumour with carcinoma-a highly aggressive salivary gland tumour

16 Félix A, El- Naggar A, Press M, Ordonez NG, Fonseca I, Tocker S, et al. Prognostic significance of biomarkers (c-erbB-2, p53, proliferating cell nuclear antigen and DNA content) in salivary duct carcinoma. Human Pathol $1996 ; 27: 561-6$

17 Press MF, Pike MC, Hung G, Zhou JY, Ma Y, George J, et al. Amplification and overexpression of HER-2/neu in carcinomas of the salivary glands: correlation with poor prognosis. Cancer Res 1994;54:5675-82.

18 Kastan MB, Onyekwere O, Sidransky D, Vogelstein B, Craig RW. Participation of $\mathrm{p} 53$ protein in the cellular response to DNA damage. Cancer Res 1991;51:6304-11.

19 Papadaki H, Finkelstein SD, Kounelis S, Bakker A, Swalsky PA, Kapadia SB. The role of p53 mutation and protein expression in primary and recurrent adenoid cystic expression in primary and recurrent 